\title{
2019 Consensus Korean Diagnostic Guidelines to Define Severity Classification and Treatment Refractoriness for Atopic Dermatitis: Objective and Subjective Assessment of Severity
}

\author{
Jung Eun Kim, Min Kyung Shin ${ }^{1}$, Gyeong-Hun Park ${ }^{2}$, Un Ha Lee ${ }^{3}$, Ji Hyun Lee, Tae-Young Han ${ }^{4}$, \\ Hyun Chang $\mathrm{Koh}^{5}$, Yong Hyun Jang ${ }^{6}$, Hye One $\mathrm{Kim}^{2}$, Chan Ho Na ${ }^{7}$, Bark-Lynn Lew ${ }^{1}$, Ji Young Ahn ${ }^{8}$, \\ Chang Ook Park ${ }^{9}$, Young Joon Seo ${ }^{10}$, Yang Won Lee ${ }^{11,12}$, Sang Wook Sohn ${ }^{13}$, Young Lip Park ${ }^{14}$ \\ Department of Dermatology, College of Medicine, The Catholic University of Korea, ${ }^{1}$ Department of Dermatology, Kyung Hee University \\ College of Medicine, Seoul, ${ }^{2}$ Department of Dermatology, Hallym University College of Medicine, Chuncheon, ${ }^{3}$ Department of Dermatology, \\ Inje University Sanggye Paik Hospital, Inje University, ${ }^{4}$ Department of Dermatology, Nowon Eulji Medical Center, Eulji University, \\ Seoul, ${ }^{5}$ Department of Dermatology, Pusan National University School of Medicine, Busan, ${ }^{6}$ Department of Dermatology, School of \\ Medicine, Kyungpook National University, Kyungpook National University Hospital, Daegu, ${ }^{7}$ Department of Dermatology, College of \\ Medicine, Chosun University, Gwangju, ${ }^{8}$ Department of Dermatology, National Medical Center, ${ }^{9}$ Department of Dermatology, Severance \\ Hospital, Cutaneous Biology Research Institute, Yonsei University College of Medicine, Seoul, ${ }^{10}$ Department of Dermatology, School of \\ Medicine, Chungnam National University, Daejeon, ${ }^{11}$ Department of Dermatology, Konkuk University School of Medicine, ${ }^{12}$ Research \\ Institute of Medical Science, Konkuk University, ${ }^{13}$ Department of Dermatology, Korea University College of Medicine, Seoul, ${ }^{14}$ Department \\ of Dermatology, Soonchunhyang University Bucheon Hospital, Bucheon, Korea
}

Background: Systemic immunomodulatory treatment is actively recommended in the treatment for moderate to severe atopic dermatitis (AD) patients. However, consensus criteria for the classification of AD severity or treatment refractoriness have not been established yet. Objective: To establish consensus criteria on the definition of severity classification and treatment refractoriness of $A D$ to provide a basis for proper treatment strategy. Methods: The Korean Atopic Dermatitis Association (KADA) comprised a task force team to establish a definition of moderate to severe AD. A draft of definition of moderate to severe $A D$ was made on the basis

Received September 11, 2019, Revised October 8, 2019, Accepted for publication October 10, 2019

Corresponding author: Yang Won Lee, Department of Dermatology, Konkuk University School of Medicine, 120-1 Neungdong-ro, Gwangin-gu, Seoul 05030, Korea. Tel: 82-2-2030-5172, Fax: 82-2-2030-5179, E-mail: 20050078 @kuh.ac.kr

ORCID: https://orcid.org/0000-0003-1268-1248

This is an Open Access article distributed under the terms of the Creative Commons Attribution Non-Commercial License (http://creativecommons. org/licenses/by-nc/4.0) which permits unrestricted non-commercial use, distribution, and reproduction in any medium, provided the original work is properly cited.

Copyright $\odot$ The Korean Dermatological Association and The Korean Society for Investigative Dermatology of evidence. The recommendation was confirmed by KADA members through a web-based survey. Results: KADA approved that AD with $16 \leq$ eczema area and severity index $($ EASI $)<23$ should be basically defined as moderate AD whereas AD with EASI score $\geq 23$ should be considered as severe AD. They agreed that it would be reasonable to raise the severity level if patient's daytime or nighttime pruritus numerical rating scale is equal to or higher than $7(\geq 7)$ or dermatology life quality index score exceeds 10 . AD patients who do not reach EASI 50 after appropriate treatment for three months should be considered as a non-responder. Patients with recurrence (EASI $\geq 16$ ) within three months after cessation of treatment should be considered as a recurrent AD. Conclusion: KADA built a consensus of definition of moderate and severe AD and treatment-refractoriness. These guidelines are expected to help physicians determine proper treatment options in need. (Ann Dermatol 31(6) 654 661, 2019)

\section{-Keywords-}

Consensus, Dermatitis, atopic, Diagnosis, Guideline, Treatment failure 


\section{INTRODUCTION}

Patients with atopic dermatitis (AD) exhibit a wide range of severity spectrum. Many publications classify the severity of $\mathrm{AD}$ as mild, moderate, and severe. However, the criteria for the classification differ according to different studies. A broad consensus has not been established yet ${ }^{1-5}$. Although a variety of instruments have been introduced to evaluate the severity of $A D$, they have relative advantages and disadvantages ${ }^{4}$. In a systematic review of sixteen instruments utilized for AD severity assessment, Schmitt et al. ${ }^{6}$ have concluded that eczema area and severity index (EASI) and the SCOring Atopic Dermatitis (SCORAD) are the best tools for measuring clinical sign of AD based on its validation, responsiveness, and inter-observer reliability. SCORAD has advantages in its responsiveness, inter-observer reliability, and interpretability ${ }^{6}$. However, it has unclear intra-observer reliability which is its disadvantage. EASI is relatively simple compared to SCORAD and quick assessment is possible. It has a scoring system that measures lesions at multiple body parts and evaluates only objective symptoms ${ }^{6}$. Various countries have adopted different $A D$ severity assessment tools. In order to reflect objective symptoms of $A D$, the European guideline used SCORAD, the Italian guideline used EASI, the United States guideline and Japan guideline used body surface area and previous Korean guideline adopted both SCORAD and $\mathrm{EASI}^{7-11}$.

Subjective symptoms of AD patients may not necessarily be proportional to objective severities of AD. Thus, assessments of subjective symptoms of itching, sleep disturbance, and quality of life (QoL) are needed to reflect correct $A D$ severity ${ }^{12}$. In particular, the EASI cannot reflect greater social problems resulting from lesions on exposed areas including head, face, neck, and hands.

Various pruritus scales and dermatology life quality index (DLQI) can specifically assess itching and QoL, respectively ${ }^{13-17}$. For measuring the severity of pruritus, visual analogue scale (VAS), numerical rating scale (NRS), and verbal rating scale have been reported to show high correlations in chronic pruritus ${ }^{18,19}$. Patients tend to have higher itch scores in NRS than in VAS. The core outcome instruments that reflect the QoL are DLQI, QoL index for AD, and Skindex. Among them, DLQI is primarily recommended since it records the highest voting score as an indicator of core outcome measurement ${ }^{20}$.

It is necessary to determine how to use these objective and subjective indices in combination for the assessment of overall disease severity. However, methods of optimal severity assessment in clinical practice or cutoffs for severity classifications vary from country to country.
Some patients with AD need systemic treatment to control their symptoms. However, they may show varied responses to treatment. Given the long-term nature of the disease, the possibility of adverse effects, and high medical costs, it is necessary to determine the degree of therapeutic response which is regarded as clinically meaningful. In addition, such information is necessary to determine whether treatment should be continued ${ }^{10,21,22}$. In addition, most patients with moderate to severe AD experience worsening of symptoms once they stop treatment for AD. However, there is no consensus on meaningful recurrence to justify more aggressive and long-term treatment. For patients who do not respond to conventional therapies or experience recurrence, new therapeutic options should be considered and an evaluation system should be established.

To provide a basis for establishing appropriate treatment strategies for patients with AD, the objective of this study was to build a consensus on severity classification and treatment refractoriness of $\mathrm{AD}$ to be used by all physicians treating AD.

\section{MATERIALS AND METHODS}

The Korean Atopic Dermatitis Association (KADA) organized a task force team to establish definitions for moderate $A D$, severe $A D$, treatment-refractory $A D$, and recurrent AD. The task force team consisted of five dermatologists who were selected based on their clinical experience and academic achievements related to AD. Members of the task force team conducted extensive literature review on severity assessment and classification criteria of AD. They set up a draft on definition of each type of $A D$ based on evidence collected. Some essential questions based on clinical experience were also developed and surveyed to recommend them as expert opinions. A total of 18 questions regarding definitions of moderate, severe, non-responder, and recurrent $\mathrm{AD}$ were developed and asked about their agreement (Table 1). To define each type of AD, both objective assessment by physicians and patients' subjective symptoms were considered.

\section{Objective assessments}

The EASI assesses erythema, edema, excoriation, and lichenification signs in four body sites (head and neck, trunk, upper extremity, and lower extremity). It is relatively less time-consuming than SCORAD index. The SCORAD index is graded as follows: mild AD, SCORAD $<25$; moderate $\mathrm{AD}, 25 \leq \mathrm{SCORAD}<50$; and severe $\mathrm{AD}$, SCORAD $\geq 50^{3,4}$. The EASI describes AD severity as follows: mild, EASI score <16; moderate, 16 $\leq$ EASI score $<23$; and severe, EASI score $\geq 23^{2,4}$. The corresponding 
Table 1. Consensus Expert Recommendations by KADA and agreement rate

\begin{tabular}{|c|c|c|}
\hline No. & Recommendations & Agreement $(\%)$ \\
\hline 1 & EASI score is suitable for use in routine clinical practice for objective assessment of AD severity and monitoring. & 97.3 \\
\hline 2 & Moderate $\mathrm{AD}$ is basically defined as an $\mathrm{AD}$ with $16 \leq \mathrm{EASI}$ score $<23$. & 97.3 \\
\hline 3 & Severe $A D$ is basically defined as an $A D$ with EASI score $\geq 23$. & 89.2 \\
\hline 4 & $\begin{array}{l}\text { To assess AD severity once before treatment is proper enough to reflect patients' } A D \text { severity in moderate } \\
\text { to severe } A D \text { patients. }\end{array}$ & 100 \\
\hline 5 & AD with EASI score $<16$, but with lesions on the face, neck, hands, foot or genitalia is defined as moderate AD. & 64.3 \\
\hline 6 & AD with $16 \leq$ EASI score $<23$, but with lesions on the face, neck, hands, foot or genitalia is defined as severe AD. & 64.9 \\
\hline 7 & To use NRS is recommended for itching scale of $A D$. & 100 \\
\hline 8 & AD with EASI score $<16$, but with daytime or night time NRS $\geq 7$ is defined as moderate AD. & 81.1 \\
\hline 9 & AD with $16 \leq$ EASI score $<23$, but with daytime or night time NRS $\geq 7$ is defined as severe AD. & 78.4 \\
\hline 10 & DLQI is recommended as a tool to assess the quality of life in AD patients. & 100 \\
\hline 11 & AD with EASI score $<16$, but with DLQI $>10$ is defined as moderate AD. & 73 \\
\hline 12 & AD with $16 \leq$ EASI score $<23$, but with DLQI $>10$ is defined as severe AD. & 73 \\
\hline 13 & To check DLQI is indicated only in patients with EASI score $<23$ and itching NRS $<7$ before treatment. & 85.3 \\
\hline 14 & $\begin{array}{l}\text { AD with allergic or non-allergic comorbidities or complications (i.e., asthma, cataract, depression) that need } \\
\text { systemic treatment should be considered as severe AD. }\end{array}$ & 62.2 \\
\hline
\end{tabular}

KADA: The Korean Atopic Dermatitis Association, EASI: eczema area and severity index, AD: atopic dermatitis, NRS: numerical rating scale, DLQI: dermatology life quality index.

Table 2. Questionnaire of dermatology life quality index (DLQI)

1. How itchy, sore, painful or stinging has your skin been?

2. How embarrassed or self-conscious have you been because of your skin?

3. How much has your skin interfered with you going shopping or looking after your home or garden?

4. How much has your skin influenced the clothes you wear?

5. How much has your skin affected any social or leisure activities?

6. How much has your skin made it difficult for you to do any sport?

7. Has your skin prevented you from working or studying?

8. How much has your skin created problems with your partner or any of your close friends or relatives?

9. How much has your skin caused any sexual difficulties?

10. How much of a problem has the treatment for your skin been, for example by making your home messy, or by taking up time?

score between EASI and SCORAD index is well validated in several literatures ${ }^{4}$. EASI of 16 corresponds to SCORAD index of 25 and EASI of 23 corresponds to SCORAD index of $50^{2}$.

In this study, we selected EASI for assessing the severity of AD in Korea based on the fact that EASI could be made without duplicating other subjective assessment systems such as VAS for itching, sleep disturbance, and QoL of AD. Whether EASI should be adopted to assess and monitor AD severity in routine clinical practice, which score of EASI is proper to define moderate to severe AD, and when would be a proper time to assess EASI are addressed in this study.

\section{Subjective assessments}

Pruritus is the chief complaint of AD patients and the key component to decide the direction of AD treatment. The task force team suggested NRS to assess pruritus in AD for its convenience to use. Patients rated intensity of itch from
0 to 10 (0: no itch; mild pruritus: $1 \leq \mathrm{NRS} \leq 3$; moderate pruritus: $4 \leq \mathrm{NRS} \leq 6$; severe pruritus: $7 \leq \mathrm{NRS} \leq 9$; 10 : worst imaginable itch) ${ }^{18}$.

DLQI is a validated tool to assess the QoL of patients with several skin diseases. DLQI comprises of ten questions in a relatively simple manner (Table 2 ). Ten questions each is scored 0 (no impact) to 3 (worst impact) on their symptoms and feelings, daily activities, leisure, work and school, personal relationships, and treatment. According to total DLQI, the following is considered: no effect: 0 to 1 ; minimal effect: 2 to 5; moderate effect: 6 to 10; large effect: 11 to 20; extremely large effect: 21 to $30^{20}$. The task force team suggested the use of DLQI to assess QoL in AD.

Standards as to what extent of decreased QoL will be judged as moderate or severe $A D$ and what improved DLQI or minimum DLQI score should be regarded as appropriate level of therapeutic effect and treatment refractoriness are asked. In the measurement of severity of itching and decreased QoL in AD, participants in our study discussed 
whether to use a single, static, or serial analysis and when it would be appropriate to check improvement of each subjective symptom scale.

\section{Voting and consensus}

Consensus of the definition was confirmed by members of the KADA through two rounds of web-based questionnaire survey in modified Delphi manner ${ }^{11}$. A total of 41 of 55 members participated in the first round of voting. They were asked whether they agreed with each statement or not. The task force team discussed results of the first round of voting and revised statements for the second round of voting, in which all voters were informed of the proportion of agreement in the first round of voting. Thirty seven out of 55 members participated in the second vote. Consensus was defined as more than $70 \%$ agreement.

\section{RESULTS}

\section{Moderate and severe AD}

Korean AD expert panel members came to an agreement about the definition of disease severity of AD. Details of the agreement are shown as follows. The agreement rate was settled by the final round of votes (Table 1).

1. Korean AD experts agreed to adopt the EASI to assess and monitor AD severity in routine clinical practice.

2. Our committee members agreed that moderate AD should be basically defined as an AD with $16 \leq$ EASI score $<23$.

3. KADA members agreed that severe AD should be basically defined as an AD with EASI $\geq 23$.

4. AD lesions wax and wane. However, because most patients with moderate to severe AD tend to be persistent in their lesions, Korean AD experts agreed that single static assessment of the EASI score before treatment could properly reflect patients' AD severity in moderate to severe AD patients.

5. The EASI score has a limitation to reflect the severity of several exposed areas such as hand, foot, and genitalia because it gives weight to the extent of certain areas. These lesion locations are directly related to social and functional impairment and low QoL. Thus, they should be separately assessed ${ }^{23,24}$. Large number of committee members agreed that $A D$ with EASI score $<16$ but with lesions on the face, neck, hands, foot, or genitalia is defined as severe AD, although this was not included in the consensus criteria. These locations are very frequently affected in AD. The presence of lesions only in these locations did not seem to be enough to upstage the disease severity. Because there has been no validated assessment tool that reflects disease severity in these specific area so far. Thus, more validated tools to assess AD severity in critically QoL-related areas needs to be developed in the future.

6. Consistently, the questionnaire that AD with $16 \leq \mathrm{EASI}$ score $<23$ but with lesions on face, neck, hands, foot, or genitalia should be defined as severe $A D$ failed to reach an agreement.

7. Korean AD experts agreed that pruritus scale should be included for assessment of AD severity and that pruritus NRS should be adopted as a pruritus scale.

8. KADA committee reached an agreement that AD with $\mathrm{EASI}<16$ but with severe pruritus (daytime or nighttime NRS $\geq 7$ ) should be considered as moderate AD and that such patients should be actively engaged in systemic immunomodulatory treatment.

9. In the same respect, they agreed that AD with $16 \leq$ EASI score $<23$, but with daytime or night time NRS $>7$ should be defined as severe AD.

10. Korean AD experts reached a consensus that DLQI should be recommended as a tool to assess QoL of patients with AD.

11. KADA agreed that patients with DLQI $>10$ should be considered as at least moderate AD even if EASI score was less than 16 .

12. They also agreed that AD with DLQI $>10$ should be considered as severe AD even if EASI score was between 16 and 23.

13. It is not necessary to check DLQI in all typical moderate to severe AD patients. DLQI should be checked in patients with EASI score $<16$ and itching NRS $\leq 7$. However, for those with low QoL, other therapeutic

Table 3. Definition of moderate and severe AD

Moderate AD is defined as an AD with EASI score $\geq 16$, or with EASI score $<16$ but at least one of the following conditions:

a. Daytime or nighttime Itch with NRS score $\geq 7$

b. DLQI $>10$

Severe $A D$ is defined as an AD with EASI score $\geq 23$, or with $16 \leq$ EASI score $<23$ but at least one of the following conditions:

a. Daytime or nighttime Itch with NRS score $\geq 7$

b. DLQI $>10$

AD: atopic dermatitis, EASI: eczema area and severity index, NRS: numerical rating scale, DLQI: dermatology life quality index. 
options should be considered to improve their life quality. For AD with $16 \leq$ EASI score $<23$ and itching NRS $\leq 7$, but with low QoL, DLQI also should be checked. Of all participants, $85.3 \%$ agreed that single static measurement for DLQI before treatment would be optimal for defining moderate to severe AD.

14. AD severity usually increases as they have more comorbidity such as asthma. Patients with ocular problem cannot use proper amount of topical steroid although they might have severer clinical manifestation. Psychologic comorbidities such as depression can decrease treatment compliance ${ }^{25}$. Obsessive behavior can aggravate $A D$ severity by vicious scratching cycle ${ }^{26}$. However, Korean AD experts failed to reach a consensus on whether AD patients with allergic or non-allergic comorbidities or complications that need systemic treatment should be considered as severe AD. The definition of moderate and severe AD were made on the basis of the agreement above and described in Table 3.

\section{Treatment-refractory $A D$ and recurrent AD}

Some AD patients are not categorized into moderate or severe $A D$ according to its definition, but they are treatment-refractory. Korean AD experts have reached a consensus that the definition of refractory or recurrent $A D$ should leave room for patients to choose new treatment options. Of Korean AD experts, 97.3\% and $81.1 \%$ agreed that definitions would be needed for non-responder and recurrent $A D$, respectively. Of all participants, $73.5 \%$ agreed that treatment refractoriness should be determined by not only EASI, but also relieving pruritus and QoL. In the same viewpoint, we adopted NRS and DLQI improvement as a tool for measuring treatment responsiveness. The following consensus recommendations and definition were achieved (Table 4, 5).

1. Refractory AD should be defined for patients with treatment refractoriness and patients who have not reached EASI 50 after three months of appropriate treatment are defined as treatment-refractory AD patients.

2. If pruritus NRS scales do not reach below NRS $<4$ after three months of appropriate treatment, such patients should be defined as treatment-refractory AD patients.

3. If DLQI score does not decrease to be below 6 after three months of appropriate treatment, patients should be defined as treatment-refractory AD patients.

4. If patients with $A D$ responded well to treatment, but developed at least moderate severity of AD lesions within three months after cessation of systemic or topical immunomodulatory treatment, such patients should be defined as recurrent AD patients.

\section{DISCUSSION}

$A D$ is increasingly being recognized as a systemic disease rather than a localized skin disease. Although systematic treatment is necessary for moderate to severe AD patients who do not respond to local therapies or who experience recurrence, an established consensus guidelines or evalua-

Table 4. Consensus Expert Recommendations on treatment-refractory and recurrent AD

\begin{tabular}{lc}
\hline \multicolumn{1}{c}{ Recommendations } & Agreement (\%) \\
\hline Treatment-refractory AD is defined as an AD who failed to reach to EASI50 after 3 months of appropriate treatment. & 94.1 \\
If pruritus NRS scales does not reach below NRS 4 after 3 months of appropriate treatment are defined as & 70.6 \\
treatment-refractory AD patients. & \\
If DLQI score does not decrease below DLQI 6 after 3 months of appropriate treatment are defined as \\
treatment-refractory AD patients. \\
Recurrent AD is defined as an AD who developed at least moderate severity of AD lesions within 3 months after \\
cessation of appropriate treatment.
\end{tabular}

AD: atopic dermatitis, EASI: eczema area and severity index, NRS: numerical rating scale, DLQI: dermatology life quality index.

Table 5. Definition of treatment-refractory $A D$ and recurrent $A D$

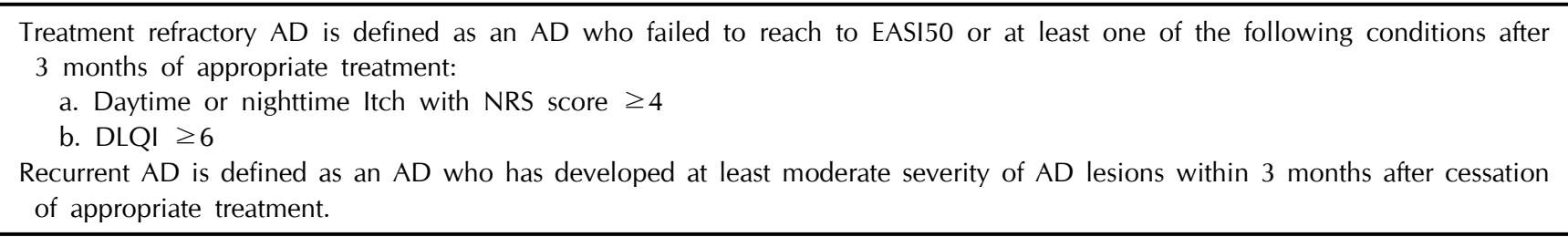

AD: atopic dermatitis, EASI: eczema area and severity index, NRS: numerical rating scale, DLQI: dermatology life quality index. 
tion system to decide moderated and severe AD is still debated upon diverse national guidelines ${ }^{7-9,11,27-29}$. Our study showed that a consensus could be made in defining moderate AD (EASI score between 16 and 23) and severe AD (EASI score over 23). Besides EASI, itching and sleep disturbance with NRS $\geq 7$ obtained an agreement rate of $78.4 \%$ to $81.1 \%$ while DLQI $>10$ obtained an agreement rate of $73 \%$ to upgrade the severity of AD. Such adjustments in the guidelines are consistent with current trends which advocate that the severity of AD should be decided by comprehensive evaluation of objective skin assessment, subjective symptoms, long-term control, relieve impairments of QoL, and functional inconveniences due to the disease. In the United States, a steering committee of AD experts including dermatologists, allergists, and a patient advocacy group representative recommended to assess the involvement of highly visible areas or those important for function (e.g., neck, face, genitals, palms, and/or soles) and QoL of the patient when evaluating the severity $^{29}$. Recently, the European guidelines defined recurrent AD as having a grade of 'moderate' and a persistent $A D$ as 'severe' ${ }^{\prime}$. This reflects how these guidelines not only consider the severity and area of skin lesions, but also the recurrence or persistence of the disease in assessing their severity. Likewise, the Italian guideline recommends that even if the EASI score is less than 16, patient with skin lesions in one's face, hands, genital area, or who experience itching and sleep disturbance with a VAS score over 7 should be considered to have a moderate to severe $A D^{10}$. However, our committee did not reach a consensus about the involvement of important location in exposed or functional areas. It is assumed that this is because there is no established standard for assessing the severity of the exposed site or genitalia which is highly controversial.

Associations with allergic and non-allergic comorbidities are being increasingly reported in moderate to severe AD. Murao et al. $^{30}$ have suggested that the severity of $A D$ should be measured by adding scores based on complications of each patient. Similarly, the Singapore Guideline recommends that $A D$ patients with psychological dysfunction should be treated as severe $\mathrm{AD}^{28}$. The Canadian guideline recommends early recognition and management of ocular comorbidities to prevent long-term sequelae and disability. Psychosomatic disease such as anxiety and depression can be an important comorbidity of moderate to severe adult $A D^{31}$. The European guideline recommends psychosomatic counseling for patients having over moderate severity and those who are unresponsive to treatment ${ }^{9}$. However, the extent or severity of complications or comorbidities to be included is not specified, making it difficult to apply it to the real world. In our committee, $62.2 \%$ of respondents agreed that the severity of AD should be upgraded in the presence of complications or comorbidities. This relatively low agreement suggests that each complication and comorbidity should be individually analyzed depending on the kind of complications and comorbidities as well as the severity in the future.

The definition or criteria of non-responsiveness to treatment remains unclear or controversial. Nonetheless, recent studies have proposed that non-responsiveness to treatment, despite appropriate dose and duration of and adherence to a therapeutic agent, may be defined by 1 or more of the following: inadequate clinical improvement, failure to achieve stable long-term disease control, presence of ongoing impairment (e.g., pruritus, pain, loss of sleep, and poor QoL) while on treatment, unacceptable adverse events or poor tolerability experienced with the treatment ${ }^{10,29}$. A high unmet need remains for novel definition or classification of treatment-refractory and recurrent or persistent AD.

According to recent literature in the Italian clinical practice, a patient with $\mathrm{AD}$ is considered a non-responder to conventional systemic immunomodulatory therapies-cyclosporine, methotrexate, and azathioprine or phototherapy when he/she has not achieved an improvement of the considered severity indices of at least $50 \%$, although the duration until the severity reaches EASI50 may vary depending on treatment ${ }^{10}$. In psoriasis guideline, drug replacement is recommended when DLQI score is over 5 even after sufficient treatment ${ }^{32}$.

We thought that following up EASI50 at post-treatment 3 months would be sufficient to expect responsiveness to treatment regardless of treatment types. According to our committee's agreement that the definition of non-responder should include indicators of improvement of subjective symptoms of patients, we propose the following: 1) If $A D$ patients will not reach to EASI50 after appropriate treatment for 3 months, they are considered as treatment-refractory AD patients; 2) If pruritus NRS scale does not reach below NRS4 or DLQI score does not decrease below DLQI 6 after 3 months of appropriate treatment, patients should be defined as treatment-refractory AD patients.

We also suggest that in the case of recurrence over moderate severity occurring within 3 months after cessation of systemic or topical treatment, these patients are considered as recurrent AD patients. Some patients may respond well to conventional systemic immunomodulatory treatment. However, they can easily relapse with moderate severity after discontinuation of treatment. Thus, recurrent AD patients are warranted to get more aggressive treatment or longer period of treatment. However, safety issue 
of long-term use of conventional systemic immunomodulatory treatment still remains. If someone AD patients responded well, but had frequent relapse with significant severity, other treatment options should be considered for such patients to prevent possible adverse effects and improve patients' QoL. Consistently, Italian guideline suggests that in the case of recurrence within 1 month after treatment discontinuation with a clinically significant increase of severity index, a treatment change should be considered. In the case of worsening AD occurring within 3 months after treatment discontinuation, a different therapeutic option may be considered ${ }^{10}$. However, there is insufficient level of information to define treatment refractory $A D$ and recurrent $A D$. The current definition of treatment refractoriness in AD could be updated based on evidence gained in the future. Our study limit is that these guidelines were developed by dermatologist group, not multidisciplinary.

We suggested guidelines for classification of severity of $\mathrm{AD}$ and treatment refractoriness that are easy to apply by clinicians. Korean AD experts reached a consensus of definitions for moderate and severe AD with EASI scoring system basically. These definitions could be modified by pruritus scale and life quality index. When judging treatment refractoriness, both objective and subjective improvement should be considered together. Treatment strategy should be decided by considering long-term control and adverse effects. Patients with moderate to severe AD, treatment refractory $A D$, or recurrent $A D$ should be treated with proper options to prevent further AD-related complications.

Moderate to severe AD patients struggle in their daily activities due to low QoL as well as high medical cost ${ }^{24,33}$. We expect that the current definition of moderate to severe $A D$ and treatment refractoriness could be utilized as standard diagnostic criteria in Korea so that physicians could get some help in determining which patients need treatment step-up or replacement.

\section{ACKNOWLEDGMENT}

This work was supported by the Korean Atopic Dermatitis Association. We appreciate the active participation and advice of 55 council members of the Korean Atopic Dermatitis Association in developing this expert opinion consensus.

\section{CONFLICTS OF INTEREST}

The authors have nothing to disclose.

\section{ORCID}

Jung Eun Kim, https://orcid.org/0000-0003-1670-0995 Min Kyung Shin, https://orcid.org/0000-0001-9834-7931 Gyeong-Hun Park, https://orcid.org/0000-0001-8890-8678 Un Ha Lee, https://orcid.org/0000-0003-1626-5583 Ji Hyun Lee, https://orcid.org/0000-0002-3671-502X Tae-Young Han, https://orcid.org/0000-0003-0317-9635 Hyun Chang Koh, https://orcid.org/0000-0002-3459-5474 Yong Hyun Jang, https://orcid.org/0000-0003-1706-007X Hye One Kim, https://orcid.org/0000-0001-5846-0008 Chan Ho Na, https://orcid.org/0000-0001-5259-5382 Bark-Lynn Lew, https://orcid.org/0000-0003-4443-4161 Ji Young Ahn, https://orcid.org/0000-0002-6766-9978 Chang Ook Park, https://orcid.org/0000-0003-3856-1201 Young Joon Seo, https://orcid.org/0000-0002-4955-590X Yang Won Lee, https://orcid.org/0000-0003-1268-1248 Sang Wook Sohn, https://orcid.org/0000-0002-3332-7056 Young Lip Park, https://orcid.org/0000-0002-6532-3156

\section{REFERENCES}

1. Boguniewicz M, Fonacier L, Guttman-Yassky E, Ong PY, Silverberg J, Farrar JR. Atopic dermatitis yardstick: practical recommendations for an evolving therapeutic landscape. Ann Allergy Asthma Immunol 2018;120:10-22.e2.

2. Chopra R, Vakharia PP, Sacotte R, Patel N, Immaneni S, White $T$, et al. Severity strata for Eczema Area and Severity Index (EASI), modified EASI, Scoring Atopic Dermatitis (SCORAD), objective SCORAD, Atopic Dermatitis Severity Index and body surface area in adolescents and adults with atopic dermatitis. Br J Dermatol 2017;177:1316-1321.

3. Kunz $B$, Oranje AP, Labrèze L, Stalder JF, Ring J, Taïeb A. Clinical validation and guidelines for the SCORAD index: consensus report of the European Task Force on Atopic Dermatitis. Dermatology 1997;195:10-19.

4. Oranje AP, Glazenburg EJ, Wolkerstorfer A, de Waard-van der Spek FB. Practical issues on interpretation of scoring atopic dermatitis: the SCORAD index, objective SCORAD and the three-item severity score. Br J Dermatol 2007;157:645-648.

5. Rajka G, Langeland T. Grading of the severity of atopic dermatitis. Acta Derm Venereol Suppl (Stockh) 1989;144: 13-14.

6. Schmitt J, Langan S, Deckert S, Svensson A, von Kobyletzki L, Thomas K, et al.; Harmonising Outcome Measures for Atopic Dermatitis (HOME) Initiative. Assessment of clinical signs of atopic dermatitis: a systematic review and recommendation. J Allergy Clin Immunol 2013;132:1337-1347.

7. Katayama I, Aihara M, Ohya Y, Saeki H, Shimojo N, Shoji S, et al; Japanese Society of Allergology. Japanese guidelines for atopic dermatitis 2017. Allergol Int 2017;66:230-247.

8. Sidbury R, Davis DM, Cohen DE, Cordoro KM, Berger TG, Bergman JN, et al.; American Academy of Dermatology. Guidelines of care for the management of atopic dermatitis: 
section 3. Management and treatment with phototherapy and systemic agents. J Am Acad Dermatol 2014;71:327-349.

9. Wollenberg A, Barbarot S, Bieber T, Christen-Zaech S, Deleuran M, Fink-Wagner A, et al.; European Dermatology Forum (EDF), the European Academy of Dermatology and Venereology (EADV), the European Academy of Allergy and Clinical Immunology (EAACl), the European Task Force on Atopic Dermatitis (ETFAD), European Federation of Allergy and Airways Diseases Patients' Associations (EFA), the European Society for Dermatology and Psychiatry (ESDaP), the European Society of Pediatric Dermatology (ESPD), Global Allergy and Asthma European Network (GA2LEN) and the European Union of Medical Specialists (UEMS). Consensusbased European guidelines for treatment of atopic eczema (atopic dermatitis) in adults and children: part II. J Eur Acad Dermatol Venereol 2018;32:850-878.

10. Calzavara Pinton P, Cristaudo A, Foti C, Canonica GW, Balato $\mathrm{N}$, Costanzo A, et al. Diagnosis and management of moderate to severe adult atopic dermatitis: a consensus by the Italian Society of Dermatology and Venereology (SIDeMaST), the Italian Association of Hospital Dermatologists (ADOI), the Italian Society of Allergy, Asthma and Clinical Immunology (SIAAIC), and the Italian Society of Allergological, Environmental and Occupational Dermatology (SIDAPA). G Ital Dermatol Venereol 2018;153:133-145.

11. Kim JE, Kim HJ, Lew BL, Lee KH, Hong SP, Jang $\mathrm{YH}$, et al. Consensus guidelines for the treatment of atopic dermatitis in Korea (part II): systemic treatment. Ann Dermatol 2015; 27:578-592.

12. Hanifin JM, Thurston M, Omoto $M$, Cherill R, Tofte SJ, Graeber $M$. The eczema area and severity index (EASI): assessment of reliability in atopic dermatitis. EASI Evaluator Group. Exp Dermatol 2001;10:11-18.

13. Finlay AY, Khan GK. Dermatology Life Quality Index (DLQI)-a simple practical measure for routine clinical use. Clin Exp Dermatol 1994;19:210-216.

14. Jenkins $H H$, Spencer ED, Weissgerber AJ, Osborne LA, Pellegrini JE. Correlating an 11-point verbal numeric rating scale to a 4-point verbal rating scale in the measurement of pruritus. J Perianesth Nurs 2009;24:152-155.

15. Majeski CJ, Johnson JA, Davison SN, Lauzon CJ. Itch Severity Scale: a self-report instrument for the measurement of pruritus severity. Br J Dermatol 2007;156:667-673.

16. Reich A, Heisig M, Phan NQ, Taneda K, Takamori K, Takeuchi $\mathrm{S}$, et al. Visual analogue scale: evaluation of the instrument for the assessment of pruritus. Acta Derm Venereol 2012; 92:497-501

17. Wahlgren CF. Children's rating of itch: an experimental study. Pediatr Dermatol 2005;22:97-101.

18. Phan NQ, Blome C, Fritz F, Gerss J, Reich A, Ebata T, et al. Assessment of pruritus intensity: prospective study on validity and reliability of the visual analogue scale, numerical rating scale and verbal rating scale in 471 patients with chronic pruritus. Acta Derm Venereol 2012;92:502-507.

19. Jang YH, Kim SM, Eun DH, Park KD, Park GH, Kim BS, et al. Validity and reliability of itch assessment scales for chronic pruritus in adults: a prospective multicenter study. J
Am Acad Dermatol 2019. doi: 10.1016/j.jaad.2019.06.043. [Epub ahead of print]

20. Chalmers JR, Simpson E, Apfelbacher CJ, Thomas KS, von Kobyletzki L, Schmitt J, et al. Report from the fourth international consensus meeting to harmonize core outcome measures for atopic eczema/dermatitis clinical trials (HOME initiative). Br J Dermatol 2016;175:69-79.

21. Paller A, Eichenfield LF, Leung DY, Stewart D, Appell M. A 12-week study of tacrolimus ointment for the treatment of atopic dermatitis in pediatric patients. J Am Acad Dermatol 2001;44(1 Suppl):S47-S57.

22. Simpson EL, Bieber T, Guttman-Yassky E, Beck LA, Blauvelt A, Cork MJ, et al.; SOLO 1 and SOLO 2 Investigators. Two phase 3 trials of dupilumab versus placebo in atopic dermatitis. N Engl J Med 2016;375:2335-2348.

23. Misery L, Seneschal J, Reguiai Z, Merhand S, Héas S, Huet F, et al. The impact of atopic dermatitis on sexual health. J Eur Acad Dermatol Venereol 2019;33:428-432.

24. Silverberg JI, Gelfand JM, Margolis DJ, Boguniewicz M, Fonacier L, Grayson $\mathrm{MH}$, et al. Patient burden and quality of life in atopic dermatitis in US adults: a population-based cross-sectional study. Ann Allergy Asthma Immunol 2018; 121:340-347.

25. DiMatteo MR, Lepper HS, Croghan TW. Depression is a risk factor for noncompliance with medical treatment: metaanalysis of the effects of anxiety and depression on patient adherence. Arch Intern Med 2000;160:2101-2107.

26. Buske-Kirschbaum A, Schmitt J, Plessow F, Romanos M, Weidinger S, Roessner V. Psychoendocrine and psychoneuroimmunological mechanisms in the comorbidity of atopic eczema and attention deficit/hyperactivity disorder. Psychoneuroendocrinology 2013;38:12-23.

27. Schneider L, Tilles $S$, Lio $P$, Boguniewicz M, Beck L, LeBovidge J, et al. Atopic dermatitis: a practice parameter update 2012. J Allergy Clin Immunol 2013;131:295-299.e1-e27.

28. Tay YK, Chan YC, Chandran NS, Ho MS, Koh MJ, Lim YL, et al. Guidelines for the management of atopic dermatitis in Singapore. Ann Acad Med Singapore 2016;45:439-450.

29. Boguniewicz M, Alexis AF, Beck LA, Block J, Eichenfield $L F$, Fonacier $L$, et al. Expert perspectives on management of moderate-to-severe atopic dermatitis: a multidisciplinary consensus addressing current and emerging therapies. J Allergy Clin Immunol Pract 2017;5:1519-1531.

30. Murao Y, Mae H, Konishi T, Gao X, Tanizawa T. Semiquantitative scoring in children under treatment for atopic dermatitis. Pediatr Int 2004;46:330-336.

31. Gooderham MJ, Hong CH, Albrecht L, Bissonnette R, Dhadwal G, Gniadecki R, et al. Approach to the assessment and management of adult patients with atopic dermatitis: a consensus document. J Cutan Med Surg 2018;22(1_suppl):3S-5S.

32. Mrowietz U, Kragballe K, Reich K, Spuls $P$, Griffiths $C E$, Nast $A$, et al. Definition of treatment goals for moderate to severe psoriasis: a European consensus. Arch Dermatol Res 2011;303:1-10.

33. Drucker AM, Wang AR, Li WQ, Sevetson E, Block JK, Qureshi AA. The burden of atopic dermatitis: summary of a report for the National Eczema Association. J Invest Dermatol 2017;137:26-30. 